\title{
Imatinib activity on Schistosoma mansoni
}

\author{
Naftale Katz ${ }^{1,2} /{ }^{+}$, Flávia Fernanda Bubulo Couto', Neusa Araújo ${ }^{1}$ \\ 'Laboratório de Esquistossomose, Centro de Pesquisas René Rachou-Fiocruz, Belo Horizonte, MG, Brasil \\ ${ }^{2}$ Academia Mineira de Medicina, Belo Horizonte, MG, Brasil
}

Imatinib, a drug used for treatment of human chronic myeloid leukaemia, due to its activity against protein kinases, has been also evaluated in vitro against Schistosoma mansoni showing high schistosomicidal activity. In the present experiments imatinib activity in vitro was confirmed at the doses of $25 \mu \mathrm{M}, 50 \mu \mathrm{M}$ and $100 \mu \mathrm{M}$. The first drug activity observed with the lower dose was interruption of egg-laying and with the higher dosages was the death of the worms. In mice infected with S. mansoni no activity was found even with 1,000 mg/kg/day, $500 \mathrm{mg} / \mathrm{kg} / \mathrm{day}$, single oral dose or when administered for three consecutive days. This is another example of the difference of results related to in vitro and in vivo trials using $\mathrm{S}$. mansoni worms.

Key words: schistosomiasis - chemotherapy - imatinib

Schistosomiasis is considered by the World Health Organization the second most important endemic parasitic disease (Bruun \& Aagaard-Hansen 2008). Two drugs very active against schistosomiasis mansoni, oxamniquine and praziquantel, have been used since the 1980s.

Nevertheless, praziquantel has been considered the drug of choice, since it presents activity against all the species of Schistosoma that affects humans and has a low cost, especially after being manufactured by the People's Republic of China and South Korea.

Praziquantel is widely used with good tolerance (Katz \& Almeida 2003), but experimental induction or selection of resistant strain and description of regions or patients, in cases when the compound is less active, indicate the need for alternative drugs to treat praziquantel-resistant schistosomiasis (Tsai et al. 2000, William et al. 2001, Bonesso-Sabadini \& Dias 2002, Doenhoff et al. 2008, Melman et al. 2009). Qi and Cui (2013), established a new schistosomiasis model for schistosomiasis with praziquantel resistance and found that from the formula of the coexistence equilibrium is easy to see that the value of the resistant strain is increased with the value of the proportion of human with drug-resistant strain produced by treatment. This means once the proportion of human with drug-resistant strain produced by drug treatment is larger, the number of human and snails with resistant strain is larger. It must also be considered that a vaccine is not yet available (Fonseca et al. 2005) and it will take several decades before developing countries will achieve a standard of sanitation similar to that in the developed world.

doi: 10.1590/0074-0276130207

Financial support: FIOCRUZ

+ Corresponding author: nkatz@cpqrr.fiocruz.br

Received 16 April 2013

Accepted 10 June 2013
Recently, it has been demonstrated that imatinib, a compound used in human chronic myeloid leukaemia therapy (Larson et al. 2008), affects Schistosoma mansoni in vitro, producing effects on gonad development, pairing stability, alterations of the gastrodermis, causing the death of the parasites. These activities of imatinib in vitro were shown to be time - and dosage - dependent and indicate that this compound must be evaluated in animal trials, as an alternative medicine for schistosomiasis (Beckmann \& Grevelding 2010).

A biochemically unusual Src/Abl hybrid kinase, SmTK6, was identified in schistosomes and confirmed Abl kinases as targets for imatinib. This drug drastically affected the morphology and survival of adult schistosomes in vitro and imatinib directly acts on, at least, one of the parasites Abl kinase (SmAbll and on SmTK6). The Abl kinase inhibitor imatinib was able to completely block SmTK6 tyrosine kinase activity, but at a 1,000X higher concentration than that needed to inhibit SmAbll tyrosine kinase - induced germinal vesicle breakdown (GVBD) (Beckmann et al. 2011). Mahanty et al. (2012) look for effects following treatment of the tapeworm Taenia crassiceps in vitro and observed that imatinib and artesunate, drugs that are not traditionally considered to treat cestodes infections, showed high activity.

In our present study, imatinib was evaluated as an antischistosomal agent in trials performed in vitro (adult worms) and in vivo, using mice experimentally infected with S. mansoni.

\section{MATERIALS AND METHODS}

In vitro trials - Mice infected with S. mansoni cercariae (LE strain) were sacrificed using sodium pentobarbital 3\% (300 $\mu \mathrm{L} /$ mice) and perfused according the technique of Smithers and Terry (1965). The collected worms were distributed into six-well-plates (4 pairs of worms/well) and were kept in culture medium RPMI1640 supplemented with 5\% foetal bovine serum, 100 $\mu \mathrm{g} / \mathrm{mL}$ penicillin/streptomycin antibiotics. In the experimental group, the worms were exposed to the compound for $24 \mathrm{~h}$ and maintained in an incubator at $37^{\circ} \mathrm{C}$ and $5 \%$ 
$\mathrm{CO}_{2}$. In the control group, the worms were kept under the same conditions, but in the absence of the compound. Afterwards, the worms were washed with culture medium and maintained under the same previous conditions, but without compounds until the end of the trial. Observations were performed using an inverted microscope and photos were taken daily for 1-24 h until seven days after the start of the culture. The culture medium was changed on alternate days. The experiments were performed in duplicate and repeated twice.

In vivo trials - Female albino mice weighing about 20 $\mathrm{g}$ were infected with $100 \pm 10$ cercariae of $S$. mansoni (LE strain) by subcutaneous route. The animals were treated 45 days post-infection. Drug administration was made by gavage, with a special needle. Imatinib (Glivec ${ }^{\circledR}$, Novartis) capsules of $400 \mathrm{mg}$ were suspended in water and administered orally. The drug administration, dose and treatment period varied according to each experimental protocol. In order to analyse the drug activity, mice were sacrificed by cervical dislocation and submitted to portal-hepatic perfusion 15 days after treatment followed by worm collection from mesenteric veins and liver. The number of worms in the liver were determined by organ compression under two glass plates and counted using a stereomicroscope (Pellegrino \& Siqueira 1956). Oogram was made from $1 \mathrm{~cm}$ of the distal part of the small intestine and eggs were classified according to the respective stages. The oogram was considered altered when one or more stages of viable eggs were absent (Pellegrino et al. 1962). In the control group, animals were infected as described, but did not receive treatment.

Activity indicators were as follows: the average number of worms, percentage distribution of worms in mesenteric veins and liver, presence of dead worms in the liver and percentage of an altered oogram when compared to the control group (Pellegrino \& Katz 1968). The results obtained were compared by means of the Student's $t$ test, $\mathrm{p} \geq 0.05$ being stipulated as significance level.

Ethics - All experiments were carried out in accordance with Brazilian regulation on the protection of animals. Ethical approval for the study was obtained from the Ethical Committee for the use of experimental animals of the Oswaldo Cruz Foundation (CEUA L-018/09).

\section{RESULTS}

Trials performed in vitro using $25 \mu \mathrm{M}$ showed that the intensity of movement of the worms diminished and only three dead eggs were found $72 \mathrm{~h}$ after the worms were removed from drug contact. With $50 \mu \mathrm{M}$ slow movements and interruption of egg-laying were complete (Figure). At $100 \mu \mathrm{M}$ morphological alterations and absence of egglaying were observed. Control worms were very active with many eggs in all stages (Figure, Table I).

Imatinib used at single oral doses of $1,000 \mathrm{mg} / \mathrm{kg} /$ day, $500 \mathrm{mg} / \mathrm{kg} /$ day or $500 \mathrm{mg} / \mathrm{kg} /$ day X 3 days for treating mice was found to be inactive, based on the mean of worms recovered, distribution of the worms at the mesenteric vessels and liver. Also, no dead worms were found in the liver and no oogram alterations were observed (Table II).
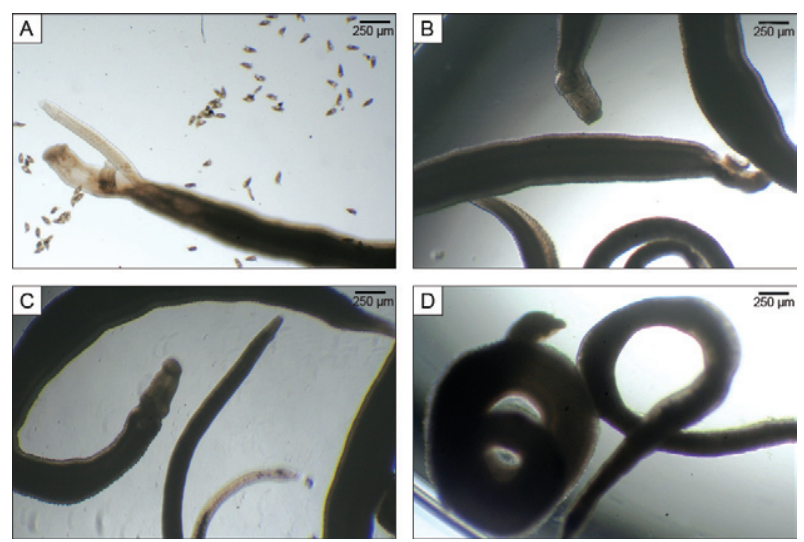

In vitro experiments. A: control worms presenting eggs at all developing stages; B-D: worms exposed to imatinib; B: worms exposed to 25 $\mu \mathrm{M}$ with absence of eggs; $\mathrm{C}$ : worms exposed to $50 \mu \mathrm{M}$ with absence of eggs; D: worms exposed to $100 \mu \mathrm{M}$ with absence of eggs, dead contracted worm seven days after treatment. Bar $=1 \mathrm{~cm}$.

\section{DISCUSSION}

Recently, it was very clearly demonstrated that imatinib, an anti-cancer compound, produces alteration of morphology, pairing stability and survival of adult $S$. mansoni in vitro (Beckmann \& Grevelding 2010). Imatinib is a competitive antagonist of adenosine triphosphate binding site, leading to inactivation of three tyrosine kinase (PDGFR, Ber-Abl and c-Kit) and interrupting downstream signalling processes (Savage \& Antman 2002). Also, it has been reported that imatinib, by intraperitoneal injection, have potent antifibrotic activity both in suppressing and reversing $S$. mansoni induced liver fibrosis (El-Agamy et al. 2011). When imatinib was used in vitro the results showed activity on S. mansoni with 10 $\mu \mathrm{M}$, but alterations were intense with $50 \mu \mathrm{M}$ or $100 \mu \mathrm{M}$, especially in females, but also in males. Confocal laser scanning microscopy clearly showed that the structure of the ovaries and oocytes was disordered. Also, the vitellarium was altered in the females treated with the highest dose $(100 \mu \mathrm{M})$. On the male worms reduction in size of the testicular lobes on spermatocytes were observed. Imatinib produces severe gastrodermis alterations in worms of both sexes (Beckmann \& Grevelding 2010).

It is interesting to remark that the protein tyrosine kinases as potential targets against human schistosomiasis has been suggested by several authors (Dissous et al. 2007, Knobloch et al. 2007) against Plasmodium falciparum (Ward et al. 2004), trypanosomes and Leishmania (Naula et al. 2005) and Ecchinococcus multilocularis larvae (Hemer \& Brehm 2012). Several compounds that are protein kinase inhibitors have been approved for cancer treatment in humans (Cohen 2009).

Our present results are in accordance with Beckmann and Grevelding (2010) as far as in vitro activity is concerned. We used only optical microscopy for assessing the decrease in movements, worm separation of couples and stop of egg-laying, starting with imatinib at the dose of $25 \mu \mathrm{M}$, being more active at $50 \mu \mathrm{M}$ and $100 \mu \mathrm{M}$. 
TABLE I

Results obtained in vitro experiments using adult Schistosoma mansoni worms exposed to imatinib

\begin{tabular}{lcc}
\hline $\begin{array}{l}\text { Imatinib } \\
(\mu \mathrm{M})\end{array}$ & $\begin{array}{c}\text { Period of } \\
\text { observation }\end{array}$ & Observations \\
\hline 25 & $24 \mathrm{~h}$ of contact & Worms: live, normal morphology, motionless. Absence of eggs. \\
50 & $24 \mathrm{~h}$ of contact & Worms: live, normal morphology, motionless. Absence of eggs. \\
100 & $24 \mathrm{~h}$ of contact & Worms: live, normal morphology, motionless. Absence of eggs. \\
- & Control & Worms: live, paired, normal movements and morphology. Presence of eggs at the first stage. \\
25 & $24 \mathrm{~h}$ after contact & Worms: live, normal morphology, motionless. Absence of eggs. \\
50 & $24 \mathrm{~h}$ after contact & Worms: live, normal morphology, motionless. Absence of eggs. \\
100 & $24 \mathrm{~h}$ after contact & Worms: live, normal morphology, motionless. Absence of eggs. \\
- & Control & Worms: live, paired, normal movements and morphology. Presence of eggs at the first and second stages. \\
25 & 48 h after contact & Worms: live, normal morphology, motionless. Absence of eggs. \\
50 & $48 \mathrm{~h}$ after contact & Worms: live, normal morphology, motionless. Two dead worms. \\
100 & $48 \mathrm{~h}$ after contact & Worms: without movement, dead worms, altered morphology. Absence of eggs. \\
- & Control & Worms: live, paired, normal movements and morphology, eggs at all development stages. \\
\hline
\end{tabular}

\section{TABLE II}

Results obtained in mice experimentally infected with $100 \pm 10$ Schistosoma mansoni cercariae (LE strain) treated with imatinib by oral route 45 days post-infection and sacrificed 15 days after treatment

\begin{tabular}{|c|c|c|c|c|c|c|c|}
\hline \multirow{2}{*}{$\begin{array}{l}\text { Treatment schedule } \\
\mathrm{mg} / \mathrm{kg} / \text { day } \mathrm{x} \text { days }\end{array}$} & \multicolumn{2}{|c|}{$\begin{array}{l}\text { Animals } \\
\text { (n) }\end{array}$} & \multirow{2}{*}{$\begin{array}{c}\text { Mean } \\
\text { worm burden }\end{array}$} & \multicolumn{2}{|c|}{$\begin{array}{c}\text { Worm distribution } \\
(\%)\end{array}$} & \multirow{2}{*}{$\begin{array}{c}\text { Liver } \\
\text { dead worm } \\
(\%)\end{array}$} & \multirow{2}{*}{$\begin{array}{c}\text { Oogram } \\
\text { changes } \\
(\%)\end{array}$} \\
\hline & Treated & Examined & & Mesentery & Liver & & \\
\hline $1000 \times 1$ & 5 & 3 & 32.7 & 86.7 & 13.3 & 0 & 0 \\
\hline $500 \times 3$ & 5 & 3 & 23.3 & 85.7 & 14.3 & 1.6 & 0 \\
\hline $500 \times 1$ & 5 & 3 & 28.3 & 92.9 & 7.1 & 0 & 0 \\
\hline Control & - & 5 & 22.8 & 90.4 & 9.6 & 0 & 0 \\
\hline
\end{tabular}

The interruption of egg-laying in vitro is a phenomenon that has been observed with other active compounds and can be considered an important sign for detecting anti-schistosomal activity. It is interesting to remark that also in vivo, in mice experimentally infected with $S$. mansoni or Schistosoma japonicum, the oogram method, which is the description of different egg stages found at the intestinal wall, has been used for drug screening since 1960s (Pellegrino et al. 1962).

When imatinib was orally administered to mice experimentally infected with $S$. mansoni, with the protocol followed in this study, no activity was detected, even at the doses of $1,000 \mathrm{mg} / \mathrm{kg}$ or $500 \mathrm{mg} / \mathrm{kg}$ that can be considered very high, when compared to the active dose used for treatment of clinical cases of myeloma leukaemia that is $400 \mathrm{mg}$ per day. Kretz et al. (2004) found that the mean fraction of imatinib in plasma $\left(\mathrm{f}_{\mathrm{p}}\right)$ was $50 \%$ in mouse and up to $92 \%$ in acute lymphatic leukaemia (AML) patients. Similarly, f for CGP74588, the primary metabolite of imatinib, was $70 \%$ in mouse and $90 \%$ in some AML patients. The failure of imatinib treatment cannot yet be explained, since the dosage of imatinib administered was very high, over 50 times higher than the clinical dose for daily treatment. Again, the discrepancy between the results obtained when comparing antischistosomal agents in vitro and in vivo has already been described (Araújo et al. 2008). Although in vitro studies are useful to generate knowledge, they are obviously limited. A medication may change depending on the specific biological processes of the organism. In vitro experiments are a simulation of the reality and they must be tied to in vivo studies, to support scientific research (Andersen et al. 2004).

\section{ACKNOWLEDGEMENTS}

Tp Dr John R Kusel, for reviewing the manuscript, to Dr Roberto Porto Fonseca, for providing the Glivec for conducting this study, and to Vera de Paula Ribeiro, for english assistance.

\section{REFERENCES}

Andersen ML, D’Almeida Vânia, Gui Mi KO, Kawakami R, Martins PJF, Magalhães L, Tufik S 2004. Principios éticos e práticos do uso de animais de experimentação, CLR Balieiro, São Paulo, 167 pp. 
Araújo N, de Mattos ACA, Coelho PMZ, Katz N 2008. Association of oxamniquine, praziquantel and clonazepam in the experimental schistosomiasis mansoni. Mem Inst Oswaldo Cruz 103: 781-785.

Beckmann S, Grevelding CG 2010. Imatinib has a fatal impact on morphology, pairing stability and survival of adult Schistosoma mansoni in vitro. Int $J$ Parasitol 40: 521-526.

Beckmann S, Hahnel S, Cailliau K, Vanderstraet M, Browaeys E, Dissous C, Grevelding CG 2011. Characterization of the Src/Abl hybrid kinase SmTK6 of Schistosoma mansoni. J Biol Chem 286: 42325-42336.

Bonesso-Sabadini PIP, Dias LCS 2002. Altered response of Schistosoma mansoni to oxamniquine and praziquantel. Mem Inst Oswaldo Cruz 97: 381-385.

Bruun B, Aagaard-Hansen J 2008. The social context of schistosomiasis and its control: an introduction and annotated bibliography, World Health Organization, Geneve, 213 pp.

Cohen P 2009. Targeting protein kinases for the development of antiinflammatory drugs. Curr Opin Cell Biol 21: 317-324.

Dissous C, Ahier A, Khayath N 2007. Protein tyrosine kinases as new potential targets against human schistosomiasis. Byoessays 29: 281-288.

Doenhoff MJ, Cioli D, Utzinger J 2008. Praziquantel: mechanisms of action, resistance and new derivatives for schistosomiasis. Curr Opin Infect Dis 21: 659-667.

El-Agamy DS, Shebl AM, Said AS 2011. Prevention and treatment of Schistosoma mansoni-induced liver fibrosis in mice. Inflammopharmacology 19: 307-316.

Fonseca CT, Cunha-Neto E, Goldberg AC, Kalil J, Jesus AR, Carvalho EM, Correa-Oliveira R, Oliveira SC 2005. Human T cell epitope mapping of the Schistosoma mansoni $14 \mathrm{kDa}$ fatty acidbinding protein using cells from patients living in areas endemic for schistosomiasis. Microbes Infect 7: 204-212.

Hemer S, Brehm K 2012. In vitro efficacy of the anticancer drug imatinib on Echinococcus multilocularis larvae. Int J Antimicrob Agents 40: 458-462.

Katz N, Almeida K 2003. Esquistossomose, xistosa, barriga d'água. Cienc Cult 55: 38-43.

Knobloch J, Beckmann S, Burmeister C, Quack T, Grevelding CG 2007. Tyrosine kinase and cooperative TGF beta signaling in the reproductive organs of Schistosoma mansoni. Exp Parasitol 117: 318-336.

Kretz O, Weiss MH, Schumacher MM, Gross G 2004. In vitro blood distribution and plasma protein binding of the tyrosine kinase inhibitor imatinib and its active metabolite, CGP74588, in rat, mouse, dog, monkey, healthy humans and patients with acute lymphatic leukaemia. Br J Clin Pharmacol 2: 212-216.

Larson RA, Druker BJ, Guilhot F, O’Brien SG, Riviere GJ, Krahnke T, Gathmann I, Wang Y 2008. Imatinib pharmacokinetics and its correlation with response and safety in chronic-phase chronic myeloid leukemia: a subanalysis of the IRIS study. Blood 111: 4022-4028.

Mahanty S, Madrid EM, Nash TE 2012. Quantitative screening for anticestode drugs based on changes in baseline enzyme secretion by Taenia crassiceps. Antimicrob Agents Chemother 57: 990-995.

Melman SD, Steinauer ML, Cunningham C, Kubatko LS, Mwangi IN, Wynn NB, Mutuku MW, Karanja DMS, Colley DG, Black CL, Secor WE, Mkoji GM, Loker ES 2009. Reduced susceptibility to praziquantel among naturally occurring Kenyan isolates of Schistosoma mansoni. PLoS NTDi 3: e504.

Naula C, Parsons M, Mottram JC 2005. Protein kinases as drugs targets in trypanosomes and Leishmania. Biochim Biophys Acta 1754: $151-159$.

Pellegrino J, Katz N 1968. Experimental chemotherapy of schistosomiasis mansoni. Adv Parasitol 6: 233-290.

Pellegrino J, Oliveira CA, Faria J, Cunha AS 1962. New approach to the screening of drugs in experimental Schistosoma mansoni in mice. Am J Trop Med Hyg 11: 201-215.

Pellegrino J, Siqueira AF 1956. Técnica de perfusão para colheita de Schistosoma mansoni em cobaias experimentalmente infectadas. Rev Bras Malariol 8: 589-597.

Qi L, Cui J 2013. A schistosomiasis model with praziquantel resistance. Discrete Dynamics in Nature and Society 2013: ID 945767.

Savage DG, Antman KH 2002. Imatinib mesylate: a new oral targeted therapy. N Eng J Med 346: 683-693.

Smithers SR, Terry RJ 1965. The infection of laboratory hosts with cercariae of Schistosoma mansoni and the recovery of adult worms. Parasitol 55: 695-700.

Tsai MH, Marx KA, Ismail MM, Tao LF 2000. Randomly amplified polymorphic DNA (RAPD) polymerase chain reaction assay for identification of Schistosoma mansoni strains sensitive or tolerant to anti-schistosomal drugs. J Parasitol 86: 146-149.

Ward P, Equinet L, Packer J, Doerig C 2004. Protein kinases of the human malaria parasite Plasmodium falciparum: the kinome of a divergent eukaryote. BMC Genomics 5: 79.

William S, Sabra A, Ramzy F, Mousa M, Demerdash Z, Bennett JL, Day TA, Botros S 2001. Stability and reproductive fitness of Schistosoma mansoni isolates with decreased sensitivity to praziquantel. Int J Parasitol 31: 1093-100. 